Atmos. Chem. Phys., 20, 10279-10293, 2020

https://doi.org/10.5194/acp-20-10279-2020

(C) Author(s) 2020. This work is distributed under

the Creative Commons Attribution 4.0 License.

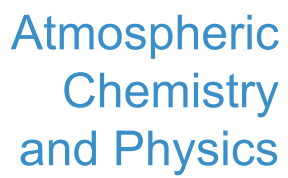

(c) (P)

\title{
Contrasting impacts of two types of El Niño events on winter haze days in China's Jing-Jin-Ji region
}

\author{
Xiaochao Yu${ }^{1,2}$, Zhili Wang ${ }^{1}$, Hua Zhang ${ }^{1}$, Jianjun $\mathrm{He}^{1}$, and $\mathrm{Ying}_{\mathbf{L i}^{3}}$ \\ ${ }^{1}$ State Key Laboratory of Severe Weather and Key Laboratory of Atmospheric Chemistry of CMA, \\ Chinese Academy of Meteorological Sciences, Beijing, 100081, China \\ ${ }^{2}$ Department of Atmospheric and Oceanic Sciences \& Institute of Atmospheric Sciences, Fudan University, Shanghai, \\ 200438, China \\ ${ }^{3}$ National Climate Center, China Meteorological Administration, Beijing, 100081, China
}

Correspondence: Zhili Wang (wangzl@cma.gov.cn)

Received: 31 December 2019 - Discussion started: 17 March 2020

Revised: 20 July 2020 - Accepted: 23 July 2020 - Published: 4 September 2020

\begin{abstract}
El Niño events differ widely in their patterns and intensities. The regional climate anomalies caused by different types of El Niño events likely lead to various impacts on winter haze pollution in China. Based on long-term site observations of haze days in China from 1961 to 2013, this study explores the effects of eastern Pacific (EP) and central Pacific (CP) types of El Niño events on the number of winter haze days (WHDs) in China's Jing-Jin-Ji (JJJ) region and the physical mechanisms underlying WHD changes. The results show statistically significant positive and negative correlations, respectively, between WHDs in the JJJ region and $\mathrm{EP}$ and CP El Niño events. At most sites in the JJJ region, the average WHD increased in all EP El Niño years, with the maximum change exceeding $2.0 \mathrm{~d}$. Meanwhile, the average WHD decreased at almost all stations over this region in all CP El Niño years, with the largest change being more than $-2.0 \mathrm{~d}$. The changes in large-scale circulations indicate obvious positive surface air temperature (SAT) anomalies and negative sea level pressure (SLP) anomalies over North China, as well as southerly wind anomalies at the middle to low troposphere over eastern China in the winters of EP El Niño years. These anomalies are conducive to increases in WHDs in the JJJ region. However, there are significant northerly and northwesterly wind anomalies at the middle to low troposphere over eastern China, as well as stronger and wider precipitation anomalies in the winters of CP El Niño years, which contribute to decreased WHDs over the JJJ region. Changes in local synoptic conditions indicate negative SLP anomalies, positive SAT anomalies, and weak-
\end{abstract}

ened northerly winds over the JJJ region in the winters of EP El Niño years. The total occurrence frequency of circulation types conducive to the accumulation (diffusion) of aerosol pollutants is increased (decreased) by $0.4 \%(0.2 \%)$ in those winters. However, the corresponding frequency is decreased (increased) by $0.5 \%(0.6 \%)$ in the winters of CP El Niño years. Our study highlights the importance of distinguishing the impacts of these two types of El Niño events on winter haze pollution in China's JJJ region.

\section{Introduction}

North China, with the Jing-Jin-Ji (JJJ) region at the core, has encountered continuous severe haze pollution in recent winters. These atmospheric calamities have seriously harmed traffic, economic development, and resident health in this region (Gao et al., 2017; Liu et al., 2017; X. Y. Zhang et al., 2019). Increased anthropogenic emissions are considered the predominant reason for the increased frequency and intensity of haze pollution. However, many studies have verified the effects of worsening local weather conditions caused by large-scale climatic anomalies on severe haze events $(\mathrm{Li}$ et al., 2016; K. Li et al., 2018; Cai et al., 2017; Yin and Wang, 2018). Anomalous meteorological conditions have significant influences on the development and maintenance of haze events; in particular, the explosive increase in local air pollutants is always accompanied by anomalous atmospheric circulation conditions (He et al., 2018; Zhang et al., 2018; 
Zhong et al., 2018). Hence, identifying the mechanism underlying the response of haze events to worsening weather conditions caused by interannual climate changes has implications for effectively controlling haze pollution and improving air quality.

As the strongest signal of interannual climate variation (Wyrtki, 1975; Cane, 2005), El Niño has an important influence on the maintenance and diffusion of air pollutants by affecting large-scale atmospheric circulation and precipitation (Feng et al., 2016a, b; Zhao et al., 2018); it consequently modulates the interannual variation of winter haze days (WHDs) in China (Gao and Li, 2015; Sun et al., 2018; He et al., 2019). Several studies have reported that an anomalous anticyclone develops over the northwest Pacific during the maturation of El Niño, resulting in increased precipitation and decreased WHDs in southern China (Li et al., 2017; Zhao et al., 2018; He et al., 2019). Moreover, atmospheric circulation anomalies caused by El Niño can exacerbate the northward transport of aerosols in South and Southeast Asia, thereby increasing winter mean aerosol concentrations (Feng et al., 2016a) and intraseasonal severe haze days in eastern China (Zhao et al., 2018; Yu et al., 2019). Recent studies have indicated that there is a significant negative correlation between El Niño and WHDs in southern China (Li et al., 2017; Zhao et al., 2018; He et al., 2019). However, the impacts of El Niño on WHDs in northern China remain controversial. For example, Sun et al. (2018) showed that El Niño led to increased WHDs in North China by suppressing the activity of the East Asian winter monsoon (EAWM). However, based on statistical analyses of long-term site observations of WHDs in China, several studies have found no statistically significant correlation between El Niño indices and WHDs in North China (Li et al., 2017; Zhao et al., 2018; He et al., 2019).

The above studies mostly focused on analyzing the comprehensive impacts of all El Niño events on WHDs in China. The results indicated that the effect of El Niño events on air pollutants in northern China was much weaker than that in southern China (Li et al., 2017; Zhao et al., 2018; He et al., 2019). However, the El Niño-Southern Oscillation (ENSO) is a complex system with two dominant modes of quasiquadrennial and quasi-biennial oscillations coexisting in the tropical Pacific (Bejarano et al., 2008; Wang and Ren, 2017). Its warm conditions (El Niño) can be classified into the eastern Pacific (EP) and central Pacific (CP) El Niño according to the anomalous sea surface temperature (SST) patterns contributed by the interplay of these independent modes (Ashok et al., 2007; Levine and Jin, 2010; Roberts et al., 2016; Timmermann et al., 2018). Because of the significantly distinct SST anomaly patterns in the equatorial Pacific, the two types of El Niño events have different influences on the Walker circulation, which further stimulates global circulation wave trains and results in contrasting temperature and precipitation anomalies in East Asia (Larkin and Harrison, 2005; Yuan and Song, 2012; Cai et al., 2018). The anomalies in regional climate caused by the two types of El Niño events may have dif- ferent influences on winter atmospheric pollutants in China. For example, using the tropospheric chemical model GEOSChem, Feng et al. (2016a) showed that CP El Niño played an important role in redistributing seasonal mean $\mathrm{PM}_{2.5}$ (particulate matter with a diameter $\leq 2.5 \mu \mathrm{m}$ ) concentrations in China. Recently, Yu et al. (2019) also found significant opposite changes in winter mean aerosol concentrations and severe haze days in North China in the responses to different types of El Niño events by using a global aerosol-climate model. Nevertheless, observation-based studies on the effects of the two types of El Niño events on haze pollutants in China are still insufficient. The JJJ region is one of the most densely populated areas in China and a typical region of severe air pollution (Cai et al., 2017; Miao et al., 2017; Zhong et al., 2018). Therefore, it is important to understand the different responses of WHDs in this region to the two types of El Niño events in greater depth.

This study first classifies different types of El Niño events according to the latest national standard of the People's Republic of China (PRC) "Identification method for El Niño/La Niña events" issued by the China Meteorological Administration (CMA) (Ren et al., 2017). Then, we explore the impacts of the two types of El Niño events on WHDs in China's $\mathrm{JJJ}$ region $\left(37-42^{\circ} \mathrm{N}, 113-120^{\circ} \mathrm{E}\right)$ from the perspectives of large-scale circulation and local synoptic condition anomalies using long-term site observations and reanalysis datasets, combined with commonly used circulation type classification methods. The datasets and methods used in this study are presented in Sect. 2. The impacts of the two types of El Niño events on WHDs in China's JJJ region and the potential physical mechanisms are analyzed in Sect. 3. The discussion and conclusions are presented in Sect. 4.

\section{Methodology}

\subsection{Data}

The datasets used in this study were as follows: (1) the monthly haze days dataset from the National Meteorological Information Center of the CMA; the time span of the dataset is from March 1961 to February 2013. According to a comprehensive judgment method widely used in previous studies, a haze day is identified when the daily mean visibility is less than $10 \mathrm{~km}$ and the daily mean relative humidity is less than $90 \%$ (Schichtel et al., 2001; Doyle and Dorling, 2002; Wu et al., 2010). (2) The monthly Niño3 index (SST anomaly averaged over the Niño3 domain 150$90^{\circ} \mathrm{W}, 5^{\circ} \mathrm{S}-5^{\circ} \mathrm{N} ; I_{\text {Niño3 }}$ ), Niño4 index (same as the Niño3 index, but over the Niño4 domain $160^{\circ} \mathrm{E}-150^{\circ} \mathrm{W}, 5^{\circ} \mathrm{S}-5^{\circ} \mathrm{N}$; $I_{\text {Niño4 }}$ ), and Niño3.4 index (same as the Niño3 index, but over the Niño3.4 domain $\left.170^{\circ}-120^{\circ} \mathrm{W}, 5^{\circ} \mathrm{S}-5^{\circ} \mathrm{N} ; I_{\mathrm{Niño} .4}\right)$ from March 1961 to February 2013 are provided by the National Climate Center of the CMA. All Niño indices are calculated using the Hadley Centre Sea Ice and Sea Surface Tempera- 
Table 1. The classification of El Niño events.

\begin{tabular}{ll}
\hline Eastern Pacific (EP) & Central Pacific (CP) \\
\hline 1963/1964, 1965/1966, 1972/1973, 1976/1977, 1979/1980, & 1968/1970, 1977/1978, 1994/1995, 2002/2003, 2004/2005, \\
$1982 / 1983,1986 / 1988,1991 / 1992,1997 / 1998,2006 / 2007$ & $2009 / 2010$ \\
\hline
\end{tabular}

ture Data (HadISST) from March 1961 to December 1981 and the National Oceanic and Atmospheric Administration (NOAA) daily optimum interpolation (OI.v2) SST dataset from January 1982 to February 2013 (Ren et al., 2017). (3) Daily and monthly ERA-40 and ERA-Interim reanalysis data from the European Centre for Medium-Range Weather Forecasts (ECMWF) include sea level pressure (SLP), air temperature at $2 \mathrm{~m}$, wind at $10 \mathrm{~m}$, geopotential height at $500 \mathrm{hPa}$, and wind from 1000 to $850 \mathrm{hPa}$ (composed of seven pressure levels at $850,875,900,925,950,975$, and $1000 \mathrm{hPa}$ ). The horizontal resolution is $0.25^{\circ} \times 0.25^{\circ}$, and the time span is from March 1961 to February 2013 for both daily and monthly reanalysis data. The data from March 1961 to December 1978 are derived from the ERA-40 reanalysis data, and the data from January 1979 to February 2013 are derived from the ERA-Interim reanalysis data. (4) The global land surface precipitation data were provided by the Global Precipitation Climatology Centre (GPCC), with a horizontal resolution of $0.5^{\circ} \times 0.5^{\circ}$, covering March 1961 to February 2013 (Schneider et al., 2014).

\subsection{Identification of two types of El Niño events and calculation of their indices}

Similar to Yu et al. (2019), we classified different types of El Niño events referring to the national standard of the PRC mentioned in Sect. 1. This method identifies El Niño events based on the widely used $I_{\mathrm{Niño3.4}}$ and employs $I_{\mathrm{Niño} 3}$ and $I_{\text {Niño4 }}$ to distinguish the different characteristics of the two types of El Niño events. $I_{\text {Niño3 }}$ and $I_{\text {Niño4 }}$ are highly sensitive to EP and CP El Niño events, respectively. This identification method has been applied to the climate operations of the CMA and has been widely used in research on the effects of El Niño events (e.g., Mu and Ren, 2017; Yu et al., 2019). We first selected all El Niño events from 1961 to 2013. An El Niño event is identified when the absolute value of the 3month running mean of $I_{\text {Niño3.4 }}$ reaches or exceeds $0.5^{\circ} \mathrm{C}$ for at least 5 months. All El Niño events were classified referring to the EP El Niño index $\left(I_{\mathrm{ep}}\right)$ and the CP El Niño index $\left(I_{\mathrm{cp}}\right)$. $I_{\mathrm{ep}}$ and $I_{\mathrm{cp}}$ were calculated as follows:

$I_{\mathrm{ep}}=I_{\mathrm{Niño3}}-\left(\alpha \cdot I_{\mathrm{Niño} 0}\right)$,

$I_{\mathrm{cp}}=I_{\mathrm{Niño} 4}-\left(\alpha \cdot I_{\mathrm{Niño} 3}\right)$.

According to an empirical formula, the constant $\alpha$ is 0.4 if $I_{\text {Niño3 }} \cdot I_{\text {Niño4 }}>0$ but 0 if $I_{\text {Niño3 }} \cdot I_{\text {Niño4 }} \leq 0$. An event is defined as an EP (CP) El Niño event if the absolute value of $I_{\mathrm{ep}}$ $\left(I_{\mathrm{cp}}\right)$ reaches or exceeds $0.5^{\circ} \mathrm{C}$ for at least 3 months. Table 1 shows the specific classifications of the two types of El Niño events obtained by the above method.

\subsection{Circulation type classification methods}

An aim of using circulation type classification is to identify the most frequently occurring subset of the meteorological data, thereby considering the numerous interrelated meteorological variables within an integrated framework and exploring the physical mechanisms underlying aerosol pollution in the JJJ region in the classification process (Richman, 1981; Miao et al., 2017). Among the multitudinous circulation classification techniques, T-mode principal component analysis (PCA) combined with the K-means cluster as used in this study is the most effective identification approach because of its reproduction of predefined types, temporal and spatial stability, and low dependence on preset parameters (Huth, 1996; Zhang et al., 2012). This method has been widely used to identify the circulation types associated with air pollution (He et al., 2017a, b, 2018). Similar to He et al. (2018), daily SLP data from March 1961 to February 2013 in the JJJ region were taken as the samples for circulation type classification. First, we reshaped three-dimensional daily SLP data, including time, latitude, and longitude, into two-dimensional data (time $\times$ grid) and normalized the two-dimensional data for time series. Second, the normalized SLP data were used to perform the T-mode PCA, and its main components were obtained according to the cumulative variance contributions up to a total of $95 \%$. Third, we clustered the main components using the K-means cluster and identified the optimal number of clusters referring to the criterion function (Genolini and Falissard, 2010). In this study, the inflection point of the criterion function, which represents the optimal number of clusters, was eight. The daily SLP data were assigned to eight synoptic-scale circulation types based on the clustering result. The other variables (e.g., temperature at $2 \mathrm{~m}$ and wind at $10 \mathrm{~m}$ ) were classified in the same way. Finally, each pattern of synoptic-scale circulation was determined.

\subsection{Correlation analysis}

The correlation coefficients of site-observed WHDs in eastern China (east of $110^{\circ} \mathrm{E}$ ) with the different types of El Niño indices (i.e., $I_{\text {Niño3.4 }}, I_{\text {ep }}$, and $I_{\text {cp }}$ ) were calculated in this study. The sites without WHDs for at least 25 consecutive years were eliminated before the correlation analysis, as the time series of WHDs at these sites lack interannual and interdecadal fluctuations, and their responses to anomalous syn- 


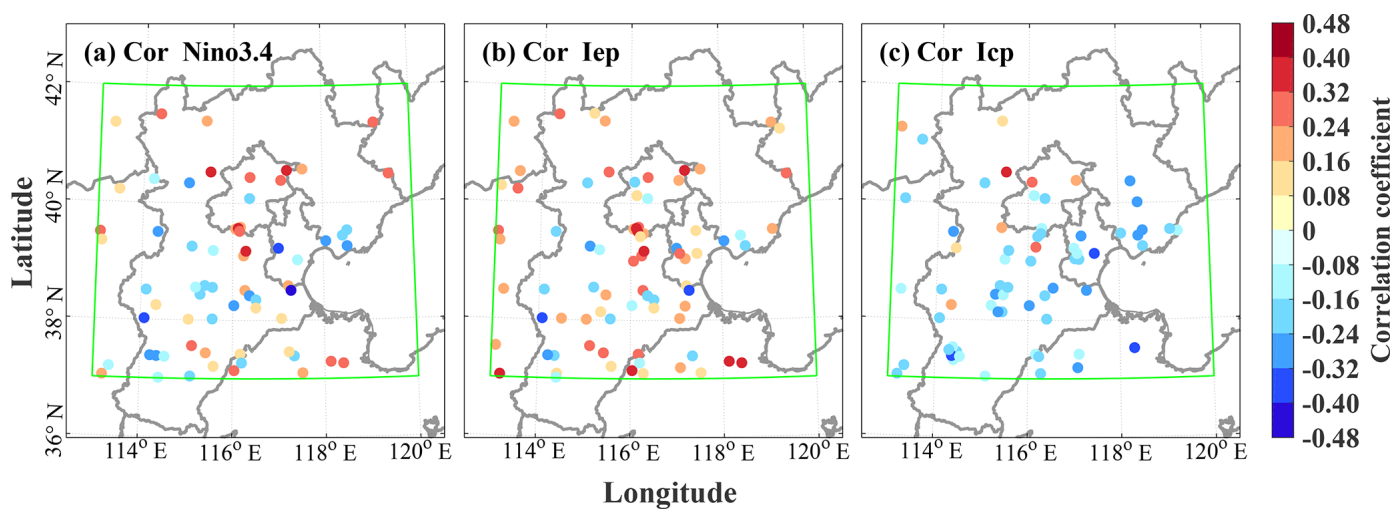

Figure 1. Correlation coefficients between the time series of site-observed winter haze days in the JJJ region and (a) $I_{\mathrm{Niño3.4}}$, (b) $I_{\mathrm{ep}}$, and (c) $I_{\mathrm{cp}}$ indices. The correlations at these sites are significant at the $90 \%$ confidence level. The green box represents the domain of the JJJ region $\left(37-42^{\circ} \mathrm{N}, 113-120^{\circ} \mathrm{E}\right)$ in this study.

optic conditions caused by climate change are weak. In addition, a band-pass filtering of 2-10 years was performed for the WHD data to remove signal interference from changes in local aerosol emissions and interdecadal climate variability following Zhao et al. (2018) and He et al. (2019). The final results more intuitively reflect the correlation between El Niño events and WHDs.

\section{Results}

\subsection{Impacts of the two types of El Niño events on WHDs in China's JJJ region}

Figure S1 in the Supplement shows the correlation coefficients for the time series of site-observed WHDs in eastern China and the $I_{\text {Niño3.4 }}, I_{\text {ep }}$, and $I_{\text {cp }}$ indices. Whether for EP or CP El Niño events, the indices feature a uniformly negative correlation with WHDs at most of the stations in southern China. This result is in agreement with previous studies (e.g., Li et al., 2017; Zhao et al., 2018; He et al., 2019), which reported that the increase in precipitation over southern China due to the anomalous anticyclone over the west Pacific during the mature phase of El Niño events significantly reduced WHDs in this region. However, for more than $60 \%$ of sites in the JJJ region, WHDs are positively correlated with the $I_{\mathrm{ep}}$ index (121 sites, accounting for $62.1 \%$ of all sites) but negatively correlated with the $I_{\mathrm{cp}}$ index (126 sites, $\left.64.6 \%\right)$. This supports the opposite impacts of the two types of El Niño events on WHDs in the JJJ region. The corresponding proportions increase to $70.5 \%$ and $86.2 \%$, respectively, if we only count the stations where the correlations pass a significance level of $90 \%$. The rest of the sites may be attributed to the disturbance of the various inducements of haze pollution, such as local emissions, weather conditions, and topography. Even though the correlations are rather low, with values hardly exceeding 0.4 at individual stations, a pattern emerges with CP El Niño being associated with fewer WHDs
Table 2. Correlation coefficients between the time series of siteaveraged winter haze days in China's JJJ region and different types of El Niño indices. The values in parentheses indicate the correlation coefficients and confidence levels when only considering the stations where the correlations pass a $90 \%$ significance level.

\begin{tabular}{lrrr}
\hline & Niño3.4 & $I_{\mathrm{ep}}$ & $I_{\mathrm{cp}}$ \\
\hline Cor & $0.04(0.06)$ & $0.16(0.31)$ & $-0.20(-0.43)$ \\
$P$ & $0.65(0.45)$ & $0.05(<0.01)$ & $0.01(<0.01)$ \\
\hline
\end{tabular}

(Fig. 1c), but a tendency of increased WHDs is obvious during EP El Niño (Fig. 1b). The correlation coefficients between the site-averaged WHDs in the JJJ region and the $I_{\mathrm{ep}}$ and $I_{\mathrm{cp}}$ indices are 0.16 and -0.2 , respectively, with a confidence level not lower than $95 \%$ (Table 2). These low correlation values likely imply a mild impact of ENSO on WHDs. Note that the corresponding correlation coefficients rise to 0.31 and -0.43 , respectively, with a confidence level of $99 \%$ when only considering the stations at which the correlations pass a significance level of $90 \%$ (Fig. 1 and Table 2).

Figure 2 shows the composite anomalies of WHDs at all sites over the JJJ region in different types of El Niño years relative to the 1961-2013 mean WHDs. For the majority of stations in the JJJ region, WHDs are increased in EP El Niño years (149 stations, $76.4 \%$ of all stations), with the maximum change exceeding $2.0 \mathrm{~d}$ (accounting for $17-79 \%$ of the average WHD; Fig. S2b in the Supplement). However, WHDs are reduced at almost all stations over this region in CP El Niño years (172 stations, $91.8 \%$ of all stations), with the maximum change exceeding $-2.0 \mathrm{~d}$ (accounting for $-13 \%$ to $-70 \%$ of the average WHD; Fig. S2c). For instance, in EP El Niño years, there are significant increases in WHDs surrounding Beijing and Tianjin, in which the positive anomalies generally exceed $1.2 \mathrm{~d}$. In CP El Niño years, the comparable negative WHD anomalies can be seen in the same region. The opposite differences in WHDs correspond- 


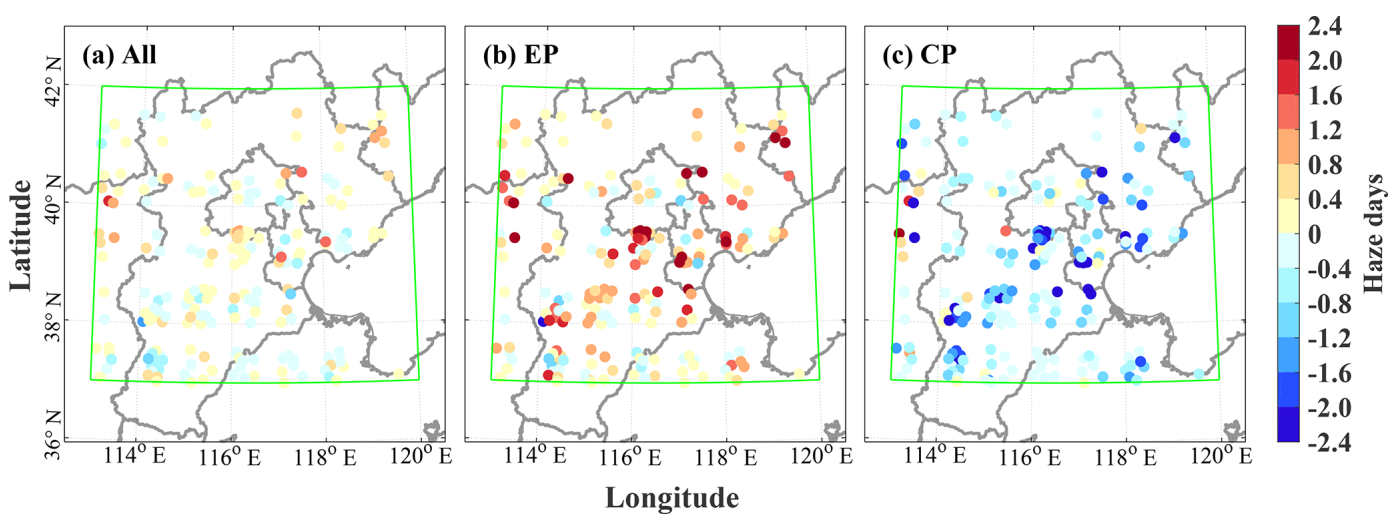

Figure 2. Composite changes in winter haze days at all sites over the JJJ region in (a) all El Niño, (b) EP El Niño, and (c) CP El Niño years relative to the 1961-2013 mean winter haze days (unit: day). The green box represents the domain of the $\mathrm{JJJ}$ region $\left(37-42^{\circ} \mathrm{N}, 113-120^{\circ} \mathrm{E}\right)$ in this study.
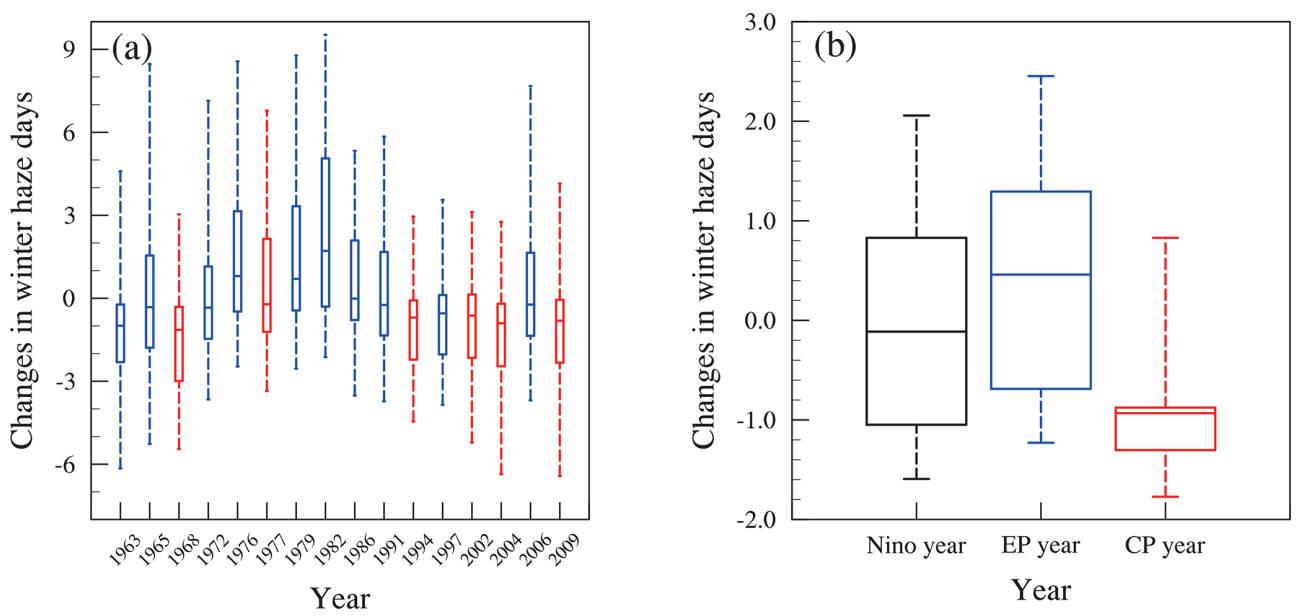

Figure 3. Box-and-whisker plots of (a) WHD anomalies at all sites over the JJJ region in each El Niño year and (b) site-averaged WHD anomalies in different types of El Niño years (unit: day). Each site-averaged WHD anomaly was sampled from a single El Niño year, and all these anomalies were divided into groups named Niño year, EP year, and CP year. The blue, red, and black lines represent the EP, CP, and all El Niño years, respectively. Each box and whisker consists of the 5th percentile (the lower point of the whisker), 25th quantile (the lower border of the box), median (horizontal line in the middle of the box), 75th quantile (the upper border of the box), and 95th percentile (the upper point of the whisker).

ing to the two types of El Niño events are also apparent in the northwestern and northeastern parts of the JJJ region. The spatial correlation coefficient between the anomalous WHDs in the JJJ region in both types of El Niño years reaches -0.71 , which is significant at the $99 \%$ level.

The detailed statistics of WHD anomalies at all sites over the JJJ region in each El Niño year are shown by the boxand-whisker plots in Fig. 3. As mentioned above, the WHD variations in the JJJ region are disturbed by local emissions, weather conditions, and topography. These result in a spread of distributions of WHD anomalies in response to individual EP or CP El Niño years. As seen in Fig. 3a, the medians of WHD anomalies for all sites are below the zero line in all CP El Niño years, indicating a negative WHD anomaly for more than half of the sites. Although the medians of WHD anomalies fluctuate above and below the zero line in different EP El Niño years, the anomalies of WHDs show obviously wider distributions in the positive range for all sites in each year, with the positive extremum exceeding $10 \mathrm{~d}$ in most EP El Niño years (data not shown in Fig. 3a). In addition, the distributions of WHD anomalies in different types of El Niño years also display interdecadal variations. The quasiquadrennial mode was significantly strong, and EP events occurred more frequently during 1980-1999, corresponding to a larger proportion and higher extremum of positive WHD anomalies for all sites in the JJJ region. After 2000, the frequency of CP El Niño events was increased, corresponding to the dominant quasi-biennial mode in the tropical Pacific, which led to a larger proportion and higher extremum of negative WHD anomalies in the JJJ region. This phenomenon 
may be attributable to the interdecadal transformation of the relative activity or stability between the two types of El Niño modes (Wang and Ren, 2017). Figure $3 \mathrm{~b}$ also shows that the WHD anomalies are mainly located in the positive range in the EP El Niño years, but are obviously located in the negative range in the $\mathrm{CP}$ El Niño years.

In summary, the impacts of the two types of El Niño events on WHDs are clearly opposite over the JJJ region. The EP El Niño events lead to increases in WHDs in the JJJ region, whereas the CP El Niño events decrease WHDs in this region. This is the reason why the correlation between the time series of WHDs over North China and the El Niño indices was found to be statistically insignificant when considering the El Niño events as a whole in previous studies (e.g., Li et al., 2017; Zhao et al., 2018; He et al., 2019).

\subsection{Anomalies of winter mean large-scale circulations for two types of El Niño}

Next, we explore the physical mechanisms underlying the WHD changes in the JJJ region in response to $\mathrm{EP}$ and $\mathrm{CP}$ El Niño events from the perspective of large-scale circulation anomalies (Fig. 4). Previous studies have found that severe haze events over North China in boreal winter are always accompanied by a decrease in northerly wind speed in the lower troposphere and weakening of the East Asian trough in the middle troposphere (Chen and Wang, 2015). The formation of heavy haze pollution over Beijing and its surroundings is significantly facilitated by the weakened EAWM, highpressure anomalies at $500 \mathrm{hPa}$, and enhanced atmospheric stability (Zhang et al., 2014; Zhong et al., 2018).

The surface air temperature (SAT) generally increases over East Asia in the winters of EP El Niño years, especially in northern China, northeastern China, and eastern Siberia, with the maximum increase reaching $2 \mathrm{~K}$ (Fig. 4a). The SLP generally drops over East Asia. In particular, the SLP is decreased more significantly north of $30^{\circ} \mathrm{N}$, with the maximum reaching $-4 \mathrm{hPa}$ in eastern Siberia (Fig. $4 \mathrm{~b}$ ). On the one hand, the worsening meteorological conditions, including near-surface warming and low pressure, are not conducive to the southward movement of the Siberian high-pressure system, thereby weakening the transport of the EAWM for aerosol pollutants over northern China. On the other hand, such conditions promote relatively stable circulation, which is conducive to the accumulation of aerosol pollutants. In addition, there is a significant positive anomaly of geopotential height at $500 \mathrm{hPa}$ over the northwestern Pacific in the winters of EP El Niño years, with the maximum anomalies exceeding $20 \mathrm{gpm}$ over southern Japan and the northwestern Pacific. These positive geopotential height anomalies also extend westward over northeastern and eastern China (Fig. 4c). At the same time, there is a negative geopotential height anomaly at $500 \mathrm{hPa}$ over southwestern China. Consequently, such a distribution of geopotential height anomalies results in an anomalous southerly wind in the middle and lower tro-
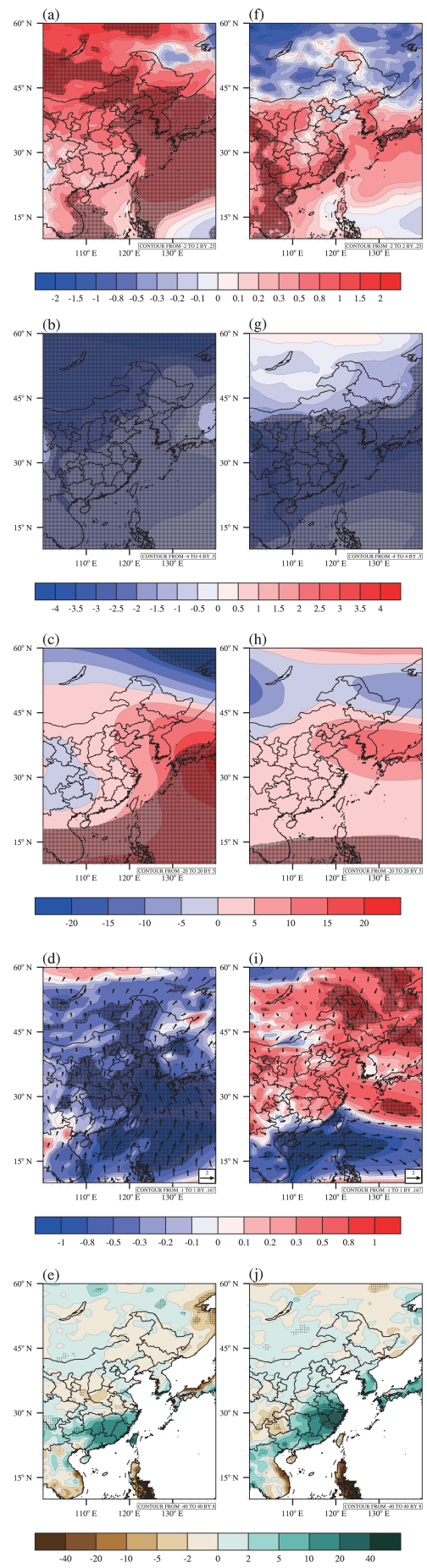

Figure 4. Winter mean changes in (a, f) air temperature at $2 \mathrm{~m}$ (unit: K), (b, g) sea level pressure (unit: hPa), (c, h) geopotential height at $500 \mathrm{hPa}$ (unit: gpm), (d, i) wind averaged from 1000 to $850 \mathrm{hPa}$ (The arrows represent wind vectors and the contours represent wind velocities, unit: $\mathrm{m} \mathrm{s}^{-1}$ ), and (e,j) precipitation (unit: $\mathrm{mm}$ ) in response to the two types of El Niño. The left (a-e) and right $(\mathbf{f}-\mathbf{j})$ panels represent the differences averaged in $10 \mathrm{EP}$ El Niño and $6 \mathrm{CP}$ El Niño years, respectively, relative to the 1961-2013 climatological means. The dots indicate significance at the $\geq 90 \%$ confidence level from a $t$ test. 
posphere over northeastern and eastern China (Fig. 4d). The anomalous southerly wind weakens the seasonal prevailing northwesterly wind in the JJJ region, with the maximum decrease exceeding $0.5 \mathrm{~ms}^{-1}$. This type of large-scale circulation anomaly suppresses the outward transport of aerosol pollutants in this region. Similar circulation anomalies were also found during the 2015-2016 superstrong EP El Niño event in an earlier study (Chang et al., 2016).

Compared to the EP El Niño years, there are larger increases in SAT and decreases in SLP over southern China in the winters of CP El Niño years, with the maximum changes reaching $0.8 \mathrm{~K}$ and $-3 \mathrm{hPa}$, respectively, over the south of the Yangtze River (Fig. 4f and g). However, the positive SAT anomalies and negative SLP anomalies over northern China in the winters of CP El Niño years are apparently weaker than the corresponding changes in the winters of EP El Niño years (Fig. 4f and g). The SAT is significantly decreased in northeastern China and Siberia, with the largest negative anomalies reaching $-2 \mathrm{~K}$. Additionally, there is an anomalous negative geopotential height at $500 \mathrm{hPa}$ over the west of Lake Baikal and the Aleutian region but a positive geopotential height at $500 \mathrm{hPa}$ over southern Japan and the Korean Peninsula in the winters of CP El Niño years (Fig. 4h). This leads to the westward shift of the East Asian trough (Jiang et al., 2017). As a result, there are northerly and northwesterly wind anomalies in the middle and lower troposphere north of $30^{\circ} \mathrm{N}$ in China, which significantly enhances the seasonal prevailing northerly wind (Fig. 4i). Such anomalous circulations are conducive to the outward transport of aerosol pollutants in the JJJ region. The monthly mean precipitation is significantly increased over eastern China in the winters of CP El Niño years, especially in the coastal regions of southeastern China, with the maximum changes exceeding $20 \mathrm{~mm}$. Precipitation is generally increased over southern China, with the maximum changes exceeding $10 \mathrm{~mm}$, but decreased slightly over central and northeastern China in the winters of EP El Niño years. The range of anomalous positive precipitation over the JJJ region is wider in CP El Niño years compared to that in EP El Niño years, although a comparable increase in precipitation over this region occurs with both types of El Niño years (Fig. 4e and j). Thus, the former is more conducive to enhancing the wet deposition of particulate matter.

Previous studies have emphasized the significant contributions to haze pollution of the formation of secondary inorganic and organic aerosols (Huang et al., 2014; Cheng et al., 2016; Wang et al., 2016). Ma et al. (2017) attributed the elevation of $\mathrm{PM}_{2.5}$ from heavy $\left(150-250 \mu \mathrm{g} \mathrm{m}^{-3}\right)$ to severe $\left(>250 \mu \mathrm{g} \mathrm{m}^{-3}\right)$ pollution to aerosol chemical conversion processes, which dominate the later stages of severe haze pollution. According to chamber studies and ambient measurements, the formation of secondary aerosols and their physical and chemical characterizations are markedly dependent on both temperature (Warren et al., 2009; Ding et al., 2011; Clark et al., 2016) and relative humidity (RH; Liu et al., 2011; Nguyen et al., 2011; Sun et al., 2013; Z. Li et al., 2018). Given the lower temperature and ozone concentrations and higher coal consumption in winter in northern China (Chen et al., 2015), heterogeneous reactions related to sulfate and nitrate, rather than photochemical reactions, are considered mostly responsible for the increased $\mathrm{PM}_{2.5}$ concentrations (Ma et al., 2017). This links the higher $\mathrm{PM}_{2.5}$ concentrations with higher $\mathrm{RH}$, as that factor contributes to these heterogeneous reactions (Cheng et al., 2016; Wang et al., 2016). However, some studies have found nonsignificant or negative correlations between RH and WHDs over northern China (Chen and Wang, 2015; Wu et al., 2016; He et al., 2019). Our results show apparently positive RH anomalies over eastern China in the winters of CP El Niño years. By contrast, increases in RH mainly occur over southern China, and RH is slightly increased or decreased over the JJJ region in the winters of EP El Niño years (Fig. S3 in the Supplement). The changes in $\mathrm{RH}$ in the middle to low troposphere over northern China in response to EP and CP El Niño years are not consistent with the corresponding variations in WHDs in the JJJ region. This indicates that the regional transport of aerosol pollutants dominates the variations of WHDs in the JJJ region in response to the two types of El Niño events, which supports the situation at the initial stage of haze occurrence as reported in Ma et al. (2017).

\subsection{Anomalies in intraseasonal local synoptic conditions in the winters of different types of El Niño years}

In this section, we further explore the different effects of the two types of El Niño events on WHDs in the JJJ region from the perspective of changes in intraseasonal local synoptic conditions. Using the T-mode PCA and K-means cluster analysis methods, eight circulation types were identified over the JJJ region in winter. The effects of the two types of El Niño events on these circulation types were then compared. The changes in local synoptic conditions are defined as the differences between the results averaged in $10 \mathrm{EP}$ (6 CP) El Niño years and the climatology.

Figures S4 and S5 in the Supplement show the climatological distributions of SLP, air temperature at $2 \mathrm{~m}$, and wind at $10 \mathrm{~m}$, respectively, over the $\mathrm{JJJ}$ region in winter for the eight circulation types. A larger northwest-southeast SLP gradient (Fig. S4a-d) and a stronger northerly wind (Fig. S5a-d) can be seen over the JJJ region for circulation types 1, 2, 3 , and 4. In particular, the high-pressure system is stronger and broader (Fig. S4a and b), and the seasonal prevailing northerly and northwesterly winds are faster (Fig. S5a and b) over the northwestern part of the JJJ region for types 1 and 2. This implies that the cold air is more active and the local aerosol pollutants are more easily transported outward under these circulation types. Conversely, there is an obviously smaller northwest-southeast SLP gradient (Fig. S4e-h) and weaker seasonal prevailing northwesterly and westerly winds 
Table 3. The occurrence frequencies of each circulation type in winter for climatology and two types of El Niño years (unit: \%). The values in parentheses represent changes relative to the climatological means.

\begin{tabular}{llrrr}
\hline & & Climatology & EP El Niño year & CP El Niño year \\
\hline Clean circulation types & T1 & $10.3 \%$ & $10.6 \%(+0.3 \%)$ & $10.3 \%(+0 \%)$ \\
& T2 & $13.1 \%$ & $13.6 \%(+0.5 \%)$ & $14.0 \%(+0.9 \%)$ \\
& T3 & $14.8 \%$ & $14.7 \%(-0.1 \%)$ & $14.9 \%(+0.1 \%)$ \\
& T4 & $15.6 \%$ & $14.7 \%(-0.9 \%)$ & $15.2 \%(-0.4 \%)$ \\
\cline { 2 - 5 } & Total & $53.8 \%$ & $53.6 \%(-0.2 \%)$ & $54.4 \%(+0.6 \%)$ \\
\hline Pollution circulation types & T5 & $17.2 \%$ & $16.6 \%(-0.6 \%)$ & $14.9 \%(-2.3 \%)$ \\
& T6 & $13.5 \%$ & $13.0 \%(-0.5 \%)$ & $15.1 \%(+1.6 \%)$ \\
& T7 & $10.6 \%$ & $10.2 \%(-0.4 \%)$ & $11.3 \%(+0.7 \%)$ \\
& T8 & $4.8 \%$ & $6.7 \%(+1.9 \%)$ & $4.3 \%(-0.5 \%)$ \\
\cline { 2 - 4 } & Total & $46.1 \%$ & $46.5 \%(+0.4 \%)$ & $45.6 \%(-0.5 \%)$ \\
\hline
\end{tabular}
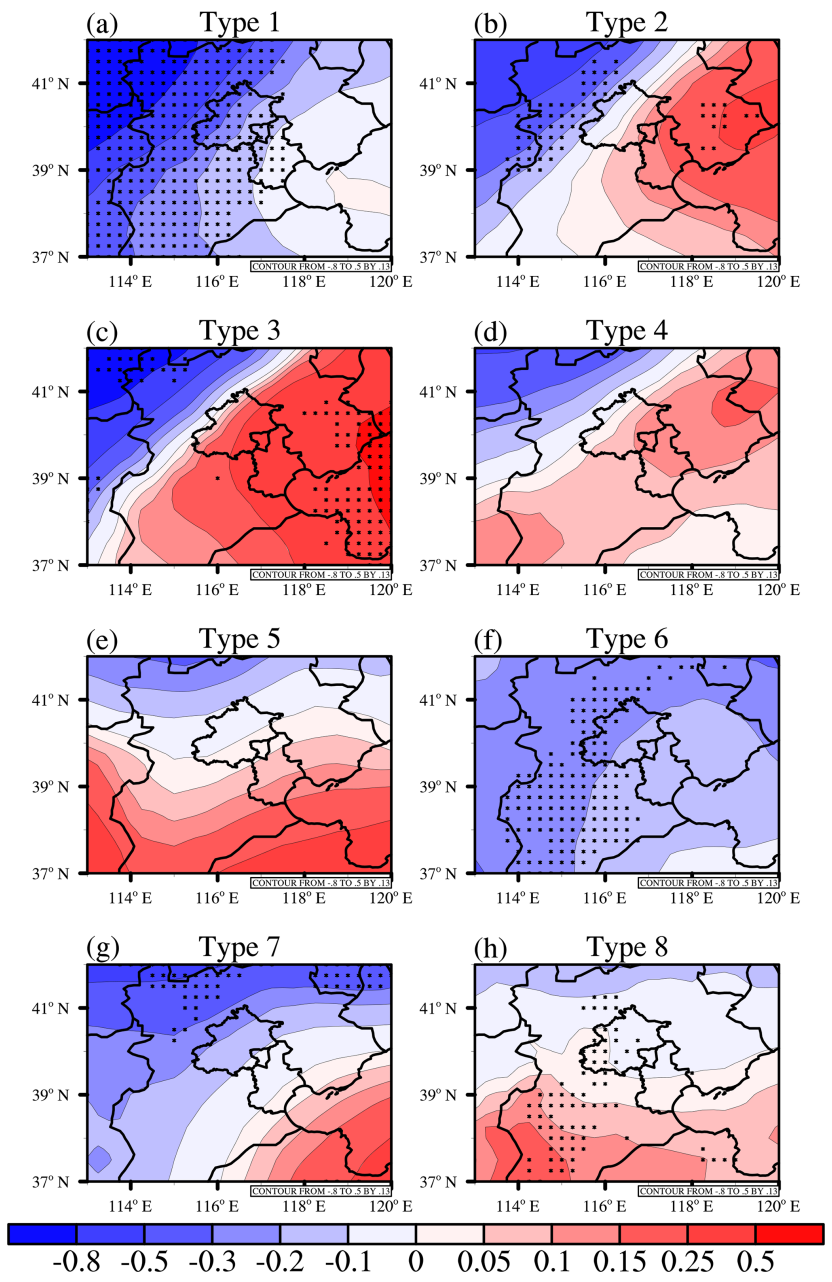

Figure 5. Changes in SLP over the JJJ region under eight circulation types in the EP El Niño years relative to the climatological means (unit: $\mathrm{hPa}$ ). The dots indicate that the differences between more than $60 \%$ of ensemble member pairs have the same sign as the mean differences.
(Fig. S5e-h) over the JJJ region for circulation types 5, 6, 7 , and 8 . Above all, there is a significant belt of low pressure in the JJJ region, and the seasonal prevailing wind becomes a southwesterly wind in the southeastern part of this region under circulation types 7 and 8 . Such circulations with low pressure and weak wind not only suppress the southward movement of cold air but also promote atmospheric stability in the JJJ region. Consequently, the local aerosol pollutants are prone to accumulating. Therefore, types $1-4$ are defined as clean circulation types and types 5-8 are defined as pollution types in this study.

Table 3 shows the occurrence frequency of clean and pollution circulation types in winter corresponding to the climatological means and the two types of El Niño years. Compared to the climatological means, it is completely opposite for the composite changes in the occurrence frequency of both pollution and clean circulation types between the two types of El Niño years. The total occurrence frequencies of clean and pollution circulation types are reduced by $0.2 \%$ and increased by $0.4 \%$, respectively, in the winters of EP El Niño years. By contrast, the corresponding frequencies are increased by $0.6 \%$ and decreased by $0.5 \%$, respectively, in the winters of CP El Niño years. These changes imply that the days conducive to the accumulation of local aerosol pollutants are increased in the winters of EP El Niño years, but the opposite occurs in the winters of CP El Niño years. Note that there are some differences among changes in the occurrence frequency of different pollution or clean circulation types. This leads to small magnitudes of the composite changes. However, the WHD anomalies corresponding to EP and CP El Niño years can generally be explained by the composite changes in the occurrence frequency of both the pollution and clean circulation types.

In the winters of EP El Niño years, there are negative SLP anomalies over the northwestern and northern parts of the JJJ region but obviously positive SLP anomalies over the southeastern and eastern parts of this region under most cir- 
culation types, except for types 1 and 6 (Fig. 5). Hence, the gradients of SLP are apparently decreased over the JJJ region for each circulation type in the winters of EP El Niño years relative to the climatological means (Fig. S4). Affected by this, southerly wind anomalies occur at the near-surface layer over the JJJ region for both clean and pollution circulation types (Fig. 7c). In addition, the anomalies of SAT over the JJJ region under most circulation types, except for types 1 and 5, are mainly distributed in the positive anomaly range, indicating that the SAT is generally increased in this region (Fig. 7a). The above analyses show decreased SLP, reduced wind velocity, and increased SAT over the JJJ region under all circulation types in the winters of EP El Niño years, which leads to a stable synoptic situation. This means that the suppression effects of pollution circulation types on the outward transport of local aerosol pollutants are enhanced over the JJJ region. At the same time, these anomalous synoptic conditions are not conducive to the southward activity of cold air, weakening the diffusion effect of clean circulation types on the local aerosol pollutants in this region.

In contrast, there are positive SLP anomalies over the northwestern and northern parts of the JJJ region but negative SLP anomalies over the southeastern or southern parts of this region under the clean circulation types in the winters of $\mathrm{CP}$ El Niño years, which increases the northwest-southeast SLP gradient (Figs. S4a-d and 6a-d). Correspondingly, the nearsurface meridional wind anomalies over the JJJ region under the clean circulation types are mainly located in the negative anomaly range (Fig. 7d), which means that the seasonal prevailing wind is enhanced in this region. Moreover, the SAT anomalies are also distributed in the negative anomaly range under the clean circulation types (Fig. 7b), indicating a significant decrease in near-surface temperature over the JJJ region. These analyses show that the intensity of synoptic situations conducive to the outward transport of local aerosol pollutants is further enhanced over the JJJ region under the clean circulation types. This may be the reason for the reduction in WHDs in this region.

In summary, there are significant differences between the impacts of the two types of El Niño events on the intraseasonal local synoptic conditions. These differences lead to opposite WHD anomalies over the JJJ region in response to different types of El Niño events. In the winters of EP El Niño years, the increase in WHDs over the JJJ region may be related to the increased days of pollution circulation types, the decreased days of clean circulation types, the enhanced suppression effect of pollution circulation types on aerosol pollutants, and the weakened diffusion effect of clean circulation types. In the winters of CP El Niño years, the reductions in WHDs in the JJJ region are mainly attributable to the increased days and intensity of clean circulation types and the decreased days of pollution circulation types.
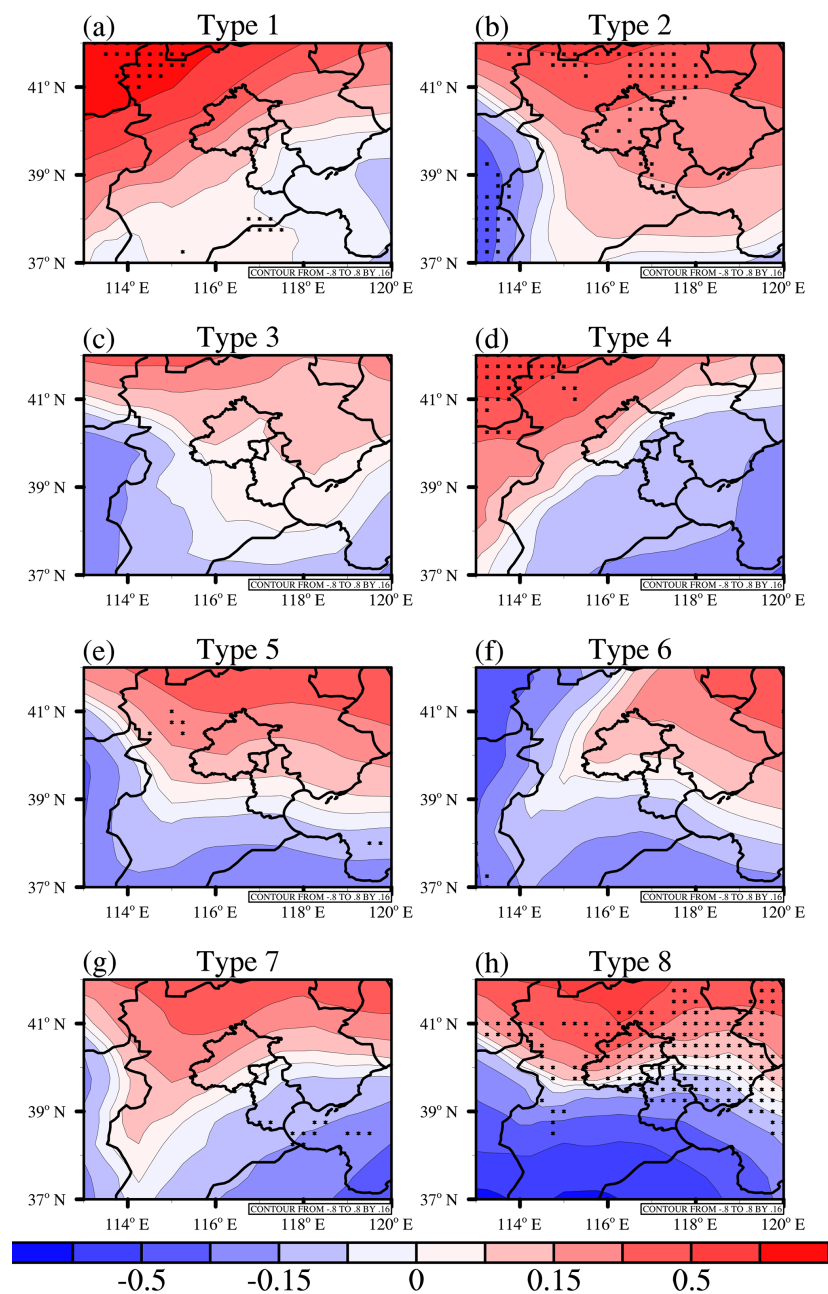

Figure 6. Changes in SLP over the JJJ region under eight circulation types in the CP El Niño years relative to the climatological means (unit: $\mathrm{hPa}$ ). The dots indicate that the differences between more than $60 \%$ of ensemble member pairs have the same sign as the mean differences.

\section{Discussion and conclusions}

Based on long-term site observations of WHDs from the CMA, the reanalysis datasets from the ECMWF, and the precipitation reanalysis data from the GPCC, this study explored the impacts of two types of El Niño events on WHDs over China's JJJ region and the potential physical mechanisms underlying their differences. The discussion and conclusions are as follows.

The effects of the two types of El Niño events on WHDs over the JJJ region are significantly different. There are statistically significant positive (negative) correlation coefficients between WHDs over the JJJ region and the $I_{\mathrm{ep}}\left(I_{\mathrm{cp}}\right)$ indices. However, the low correlations likely imply a mild impact of the ENSO on WHDs. Correspondingly, WHDs increase (decrease) over the JJJ region in the winters of EP (CP) El Niño years. Our results are obviously different from those in pre- 

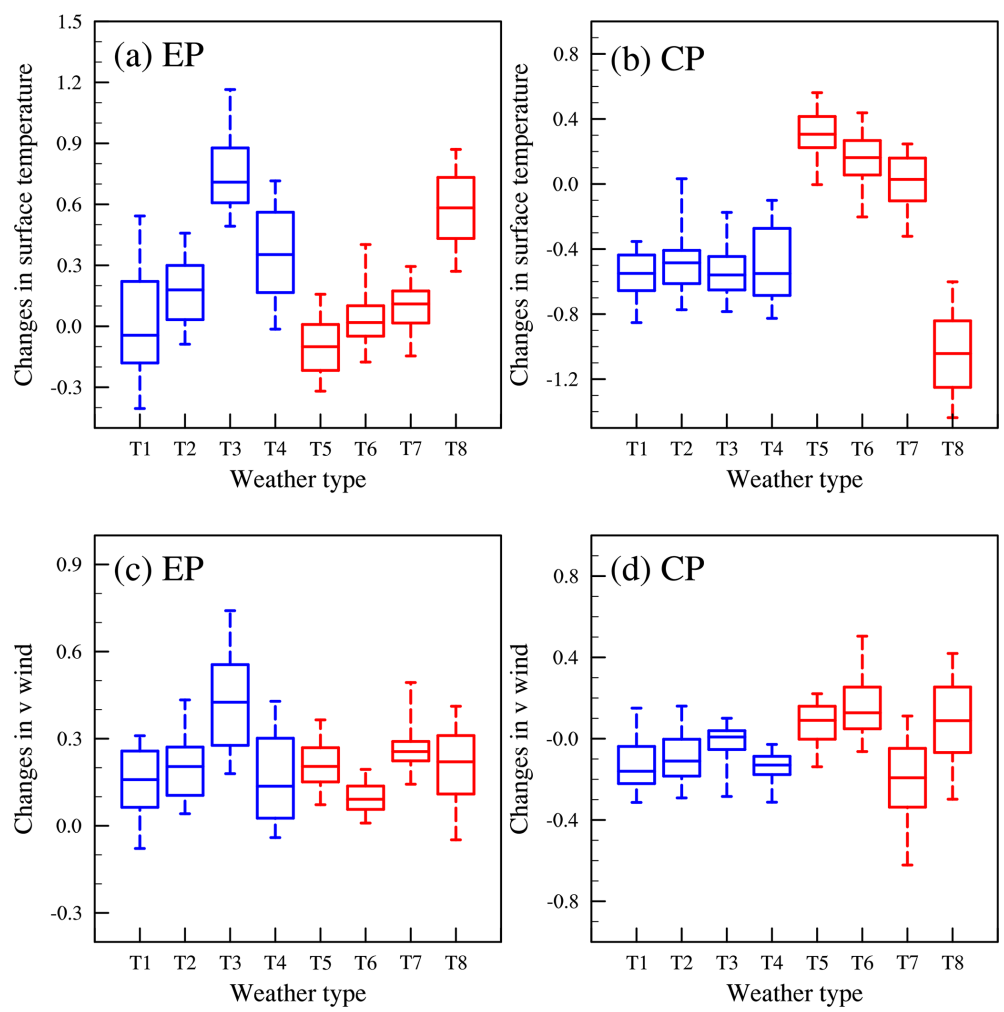

Figure 7. Box-and-whisker plots of anomalies of (a, b) temperature at $2 \mathrm{~m}$ (unit: $\mathrm{K}$ ) and (c, d) meridional wind at $10 \mathrm{~m}$ (unit: $\mathrm{m} \mathrm{s}^{-1}$ ) over the JJJ region under eight circulation types for different types of El Niño years. The blue and red lines represent the clean and pollution circulation types, respectively. Each box and whisker consists of the 5th percentile (the lower point of the whisker), 25th quantile (the lower border of the box), median (horizontal line in the middle of the box), 75th quantile (the upper border of the box), and 95th percentile (the upper point of the whisker).

vious studies without distinguishing two types of El Niño events (e.g., Li et al., 2017; Sun et al., 2018; Zhao et al., 2018; He et al., 2019), which reported statistically insignificant effects of El Niño on winter haze pollution in North China.

Figure 8 shows the physical mechanisms corresponding to the effects of the EP and CP El Niño on WHDs in the $\mathrm{JJJ}$ region. The changes in large-scale circulation at the near surface and middle to low troposphere in East Asia are significantly different in response to the two types of El Niño events, which consequently leads to the opposite effects on WHDs over the JJJ region. There are increases in SAT and decreases in SLP over North China in the winters of EP El Niño years. Simultaneously, the seasonal prevailing wind is weakened due to a large range of southerly wind anomalies over the middle to low troposphere in this region. These anomalies suggest that the activity of the EAWM is significantly suppressed and the intensity of cold air is weakened, both of which are conducive to the concurrent increases in WHDs over the JJJ region. By contrast, meteorological anomalies, such as near-surface warming and low pressure, are apparent over southern China in the winters of $\mathrm{CP}$ El Niño years. The westward shift of the East Asian trough at $500 \mathrm{hPa}$ leads to northerly and northwesterly wind anomalies over the middle to low troposphere in eastern China, which significantly enhances the seasonal prevailing wind. This may result in the decrease in WHDs over the JJJ region during the same period. Furthermore, the positive precipitation anomalies over eastern China are stronger in intensity and wider ranging in the winters of CP El Niño years, which also contributes to the reduction in WHDs over the JJJ region.

Our results further indicate an increase in the total occurrence frequency of pollution circulation types and a decrease in that of clean circulation types in the winters of EP El Niño years. These changes support the accumulation and maintenance of local aerosol pollutants in the JJJ region. In addition, there are obvious synoptic condition anomalies, including the reduced SLP gradient, near-surface warming, and weakened northerly wind, over the JJJ region under all circulation types. These changes indicate enhanced pollution and weakened clean circulation types in the winters of EP El Niño years, which may be one reason for the increased WHDs over the JJJ region. Conversely, the reductions in WHDs over the JJJ region are mainly attributable to the increase (decrease) in the total occurrence frequency of clean (pol- 

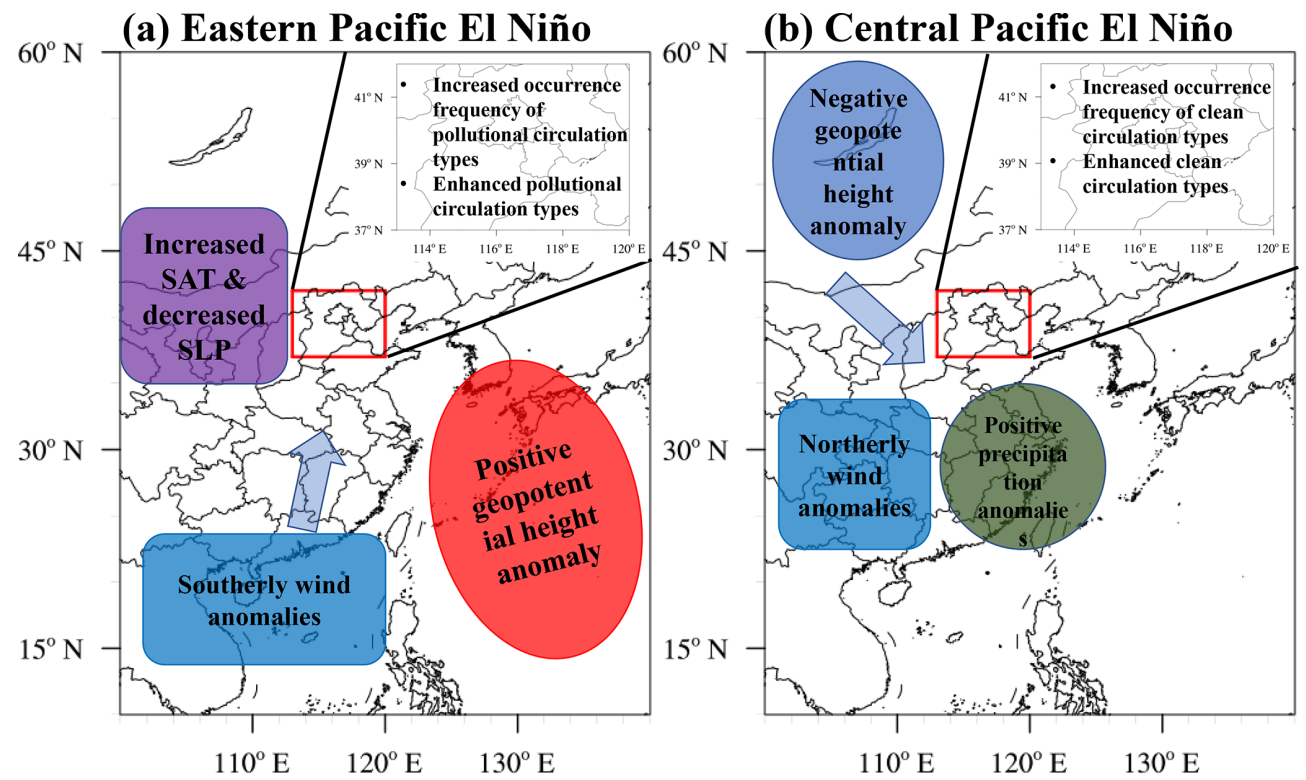

Figure 8. Schematic diagrams showing the physical mechanisms of the effects of (a) eastern Pacific and (b) central Pacific El Niño on WHDs in the $\mathrm{JJJ}$ region.

lution) circulation types in the winters of CP El Niño years. These anomalous changes result in increased cold air days and thereby facilitate the outward transport of local aerosol pollutants. Meanwhile, the intensity of cold air is enhanced due to the larger SLP gradient, negative temperature anomalies, and stronger near-surface northerly winds over the JJJ region under the clean circulation types. These anomalies likely contribute to the reduction in WHDs in this region.

In recent years, the air quality improvement projects implemented by China's government have effectively controlled the emissions of $\mathrm{PM}_{2.5}$ in most areas of China (Zheng et el., 2018; Ding et al., 2019; Gui et al., 2019; Q. Zhang et al., 2019). However, haze pollution events continue to occur (X. Y. Zhang et al., 2019). The impacts of worsening meteorological conditions caused by annual climate change on the haze pollution process are worthy of concern. This study elucidates the potential physical mechanisms of WHD changes over the JJJ region in response to two types of El Niño events from the perspectives of large-scale circulation and local synoptic condition anomalies. As reported by $\mathrm{Yu}$ et al. (2019), we further emphasized the importance of distinguishing the effects of the two types of El Niño events on winter haze pollution in North China. This study has certain implications for further understanding the impact of climate changes on air pollution in China's regions. Note that El Niño has the potential to change the composition and size distribution of aerosols by affecting aerosol transport, deposition, and chemical reactions, which are central to haze pollution (Li et al., 2011; Shaheen et al., 2013; Rajeev et al., 2016; Jayarathne et al., 2018). According to our results, we attribute the variations in WHDs in the JJJ region in
El Niño years to the impact of El Niño on the regional transport of aerosols. However, overall aerosol processes related to El Niño could not be precisely characterized at present, as there are few long-term, large-scale observations of aerosol composition, particle types, and size distribution in China. More detailed analyses need to be completed by gathering more observations and performing more sensitive simulations in future work. In addition, winter haze pollution in China may also be affected by multiple-timescale climate change factors, including the EAWM (Kim et al., 2017), Arctic Oscillation (Chen et al., 2013), Arctic sea ice (Wang and Chen, 2016), Tibetan Plateau heat source (Xu et al., 2016), and interdecadal variation in snow cover (Yin and Wang, 2018). Future research should consider how to quantify the comprehensive contributions of different climate change factors to haze pollution in China.

Data availability. The monthly haze days dataset from the $\mathrm{Na}-$ tional Meteorological Information Center, China Meteorological Administration, is currently not available for the public to download. The monthly Niño3, Niño4, and Niño3.4 indices are available at http://cmdp.ncc-cma.net/download/Monitoring/ Index/M_Oce_Er.txt (last access: 10 September 2017) (CMA, 2017). Daily and monthly ERA-40 and ERA-Interim reanalysis data are available at https://www.ecmwf.int/en/forecasts/ datasets/browse-reanalysis-datasets (last access: 29 August 2020) (ECMWF, 2020). The global land surface precipitation data can be acquired from https://climatedataguide.ucar.edu/climate-data (last access: 29 August 2020) (GPCC, 2020). 
Supplement. The supplement related to this article is available online at: https://doi.org/10.5194/acp-20-10279-2020-supplement.

Author contributions. ZW conceived the study. XY, ZW, and HZ performed the analysis and led the paper writing. All authors provided comments and contributed to the text.

Competing interests. The authors declare that they have no conflict of interest.

Financial support. This research has been supported by the Key National Natural Science Foundation of China (grant no. 91644211) and the National Key Research and Development Program of China (grant no. 2016YFC0203306).

Review statement. This paper was edited by Patrick Jöckel and reviewed by two anonymous referees.

\section{References}

Ashok, K., Behera, S. K., and Rao, S. A.: El Niño Modoki and its possible teleconnection, J. Geophys. Res.-Oceans, 112, C11007, https://doi.org/10.1029/2006jc003798, 2007.

Bejarano, L. and Jin, F. F.: Coexistence of equatorial coupled modes of ENSO, J. Climate, 21, 3051-3067, https://doi.org/10.1175/2007jcli1679.1, 2008.

Cai, W. J., Li, K., Liao, H., Wang, H. J., and Wu, L. X.: Weather conditions conducive to Beijing severe haze more frequent under climate change, Nat. Clim. Change, 7, 257-262, https://doi.org/10.1038/nclimate3249, 2017.

Cai, W. J., Wang, G. J., Dewitte, B., Wu, L. X., Santoso, A., Takahashi, K, Yun, Y., Carréric, A., and McPhaden, J. M.: Increased variability of eastern Pacific El Niño under greenhouse, Nature, 564, 201-206, https://doi.org/10.1038/s41586-018-0776-9, 2018.

Cane, M. A.: The evolution of El Niño, past and future, Earth Planet. Sc. Lett., 230, 227-240, https://doi.org/10.1016/j.epsl.2004.12.003, 2005.

Chang, L. Y., Xu, J. M., Tie, X. X., and Wu, J. B.: Impact of the 2015 El Nino event on winter air quality in China, Sci. Rep.-UK, 6, 34275, https://doi.org/10.1038/srep34275, 2016.

Chen, H. P. and Wang, H. J.: Haze Days in North China and the associated atmospheric circulations based on daily visibility data from 1960 to 2012, J. Geophys. Res.-Atmos., 120, 5895-5909, https://doi.org/10.1002/2015jd023225, 2015.

Chen, X., Huang, F. X., Xia, X. Q., Cao, J., and Xu, X. B.: Analysis of tropospheric ozone long-term changing trends and affecting factors over northern China (in Chinese), Chinese Sci. Bull., 60, 2659-2666, https://doi.org/10.1360/N972015-00155, 2015.

Chen, W., Lan, X. Q., Wang, L., and Ma, Y.: The combined effects of the ENSO and the Arctic Oscillation on the winter climate anomalies in East Asia, Chinese Sci. Bull., 58, 1355-1362, https://doi.org/10.1007/s11434-012-5654-5, 2013.
Cheng, Y. F., Zheng, G. J., Wei, C., Mu, Q., Zheng, B., Wang, Z. B., Gao, M., Zhang, Q., He, K. B., Carmichael, G., Pöschl, U., and $\mathrm{Su}, \mathrm{H}$.: Reactive nitrogen chemistry in aerosol water as a source of sulfate during haze events in China, Sci. Adv., 2, e1601530 e1601530, https://doi.org/10.1126/sciadv.1601530, 2016.

Clark, C. H., Kacarab, M., Nakao, S., Asa-Awuku, A., Sato, K., and Cocker, D. R.: Temperature Effects on Secondary Organic Aerosol (SOA) from the Dark Ozonolysis and PhotoOxidation of Isoprene, Environ. Sci. Technol., 50, 5564-5571, https://doi.org/10.1021/acs.est.5b05524, 2016.

CMA: Monthly Niño indices, available at: http://cmdp.ncc-cma. net/download/Monitoring/Index/M_Oce_Er.txt, last access: 10 September 2017.

Ding, A., Huang, X., Nie, W., Chi, X., Xu, Z., Zheng, L., Xu, Z., Xie, Y., Qi, X., Shen, Y., Sun, P., Wang, J., Wang, L., Sun, J., Yang, X.-Q., Qin, W., Zhang, X., Cheng, W., Liu, W., Pan, L., and Fu, C.: Significant reduction of $\mathrm{PM}_{2.5}$ in eastern China due to regional-scale emission control: evidence from SORPES in 2011-2018, Atmos. Chem. Phys., 19, 11791-11801, https://doi.org/10.5194/acp-19-11791-2019, 2019.

Ding, X., Wang, X. M., and Zheng, M.: The influence of temperature and aerosol acidity on biogenic secondary organic aerosol tracers: Observations at a rural site in the central Pearl River Delta region, South China, Atmos. Environ., 45, 1303-1311, https://doi.org/10.1016/j.atmosenv.2010.11.057, 2011.

Doyle, M. and Dorling, S.: Visibility trends in the UK 1950-1997, Atmos. Environ., 36, 3161-3172, https://doi.org/10.1016/s13522310(02)00248-0, 2002.

ECMWF: Reanalysis data sets, available at: https://www.ecmwf. int/en/forecasts/datasets/browse-reanalysis-datasets, last access: 29 August 2020.

Feng, J., Li, J. P., Zhu, J. L., and Liao, H.: Influences of El Niño Modoki event 1994/1995 on aerosol concentrations over southern China, J. Geophys. Res.-Atmos., 121, 1637-1651, https://doi.org/10.1002/2015jd023659, 2016a.

Feng, J., Zhu, J. L., and Li, Y.: Influences of El Niño on aerosol concentrations over eastern China, Atmos. Sci. Lett., 17, 422430, https://doi.org/10.1002/asl.674, 2016b.

Gao, H. and Li, X.: Influences of El Nino Southern Oscillation events on haze frequency in eastern China during boreal winters, Int. J. Climatol., 35, 2682-2688, https://doi.org/10.1002/joc.4133, 2015.

Gao, J. H., Woodward, A., Vardoulakis, S., Vardoulakis, S., Kovats, S., Wilkinson, P., Li, J. P., Xu, L., Li, J., Yang, J., Li, J., Cao, L. N., Liu, X. B., Wu, H. X., and Liu, Q. Y.: Haze, public health and mitigation measures in China: A review of the current evidence for further policy response, Sci. Total Environ., 578, 148-157, https://doi.org/10.1016/j.scitotenv.2016.10.231, 2017.

Genolini, C. and Falissard, B.: KmL: $k$-means for longitudinal data, Computation. Stat., 25, 317-328, https://doi.org/10.1007/s00180-009-0178-4, 2010.

GPCC: Land surface precipitation reanalysis, available at: https: //climatedataguide.ucar.edu/climate-data, last access: $29 \mathrm{Au}-$ gust 2020.

Gui, K., Che, H. Z., Wang, Y. Q., Wang, H., Zhang, L., Zhao, H. J., Zheng, Y., Sun, T. Z., and Zhang, X. Y.: Satellite-derived $\mathrm{PM}_{2.5}$ concentration trends over Eastern China from 1998 to 2016: Relationships to emissions and me- 
teorological parameters, Environ. Pollut, 247, 1125-1133, https://doi.org/10.1016/j.envpol.2019.01.056, 2019.

He, C., Liu, R., Wang, X. M., Liu, S. C., Zhou, T. J., and Liao, W. H.: How does El Niño-Southern Oscillation modulate the interannual variability of winter haze days over eastern China?, Sci. Total Environ., 651, 1892-1902, https://doi.org/10.1016/j.scitotenv.2018.10.100, 2019.

He, J. J., Gong, S. L., Liu, H. L., An, X. Q., Zhao, S. P., Wu, L., Song, C. B., Zhou, C. H., Wang, J., Yin, C. M., and Yu, L. J.: Influences of meteorological conditions on interannual variations of particulate matter pollution during winter in the Beijing-Tianjin-Hebei area, J. Meteorol. Res.-PRC, 31, 10621069, https://doi.org/10.1007/s13351-017-7039-9, 2017a.

He, J. J., Gong, S. L., Yu, Y., Yu, L. J., Wu, L., Mao, H. J., Song, C. B., Zhao, S. P., Liu, H. L., Li, X. Y., and Li, R. P.: Air pollution characteristics and their relation to meteorological conditions during 2014-2015 in major Chinese cities, Environ. Pollut., 223, 484-496, https://doi.org/10.1016/j.envpol.2017.01.050, $2017 \mathrm{~b}$.

He, J. J., Gong, S. L., Zhou, C. H., Lu, S. H., Chen, Y., Yu, Y., Zhao, S. P., Yu, L. J., and Yin, C. M.: Analyses of winter circulation types and their impacts on haze pollution in Beijing, Atmos. Environ., 192, 94-103, https://doi.org/10.1016/j.atmosenv.2018.08.060, 2018.

Huang, R. J., Zhang, Y. L., Bozzetti, C., Ho, K. F., Cao, J. J., Han, Y. M., Daellenbach, K. R., Slowik, J. G., Platt, S. M., Canonaco, F., Zotter, P., Wolf, R., Pieber, S. M., Bruns, E. A., Crippa, M., Ciarelli, G., Piazzalunga, A., Schwikowski, M., Abbaszade, G., Schnelle-Kreis, J., Zimmermann, R., An, Z. S., Szidat, S., Baltensperger, U., Haddad, I. E., and Prévôt, A. S. H.: High secondary aerosol contribution to particulate pollution during haze events in China, Nature, 514, 218-222, https://doi.org/10.1038/nature13774, 2014.

Huth, R.: An intercomparison of computer-assisted circulation classification methods, Int. J. Climatol., 16, 893-922, https://doi.org/10.1002/(sici)1097-0088(199608)16:8<893::aidjoc51>3.0.co;2-q, 1996.

Jayarathne, T., Stockwell, C. E., Gilbert, A. A., Daugherty, K., Cochrane, M. A., Ryan, K. C., Putra, E. I., Saharjo, B. H., Nurhayati, A. D., Albar, I., Yokelson, R. J., and Stone, E. A.: Chemical characterization of fine particulate matter emitted by peat fires in Central Kalimantan, Indonesia, during the 2015 El Niño, Atmos. Chem. Phys., 18, 2585-2600, https://doi.org/10.5194/acp-18-2585-2018, 2018.

Jiang, Y. Q., Yang, X. Q., Liu, X. H., Yang, D. J., Sun, X. G., Wang, M. H., Ding, A. J., Wang, T. J., and Fu, C. B.: Anthropogenic aerosol effects on East Asian winter monsoon: The role of black carbon induced Tibetan Plateau warming, J. Geophys. Res.Atmos., 122, 5883-5902, https://doi.org/10.1002/2016jd026237, 2017

Kim, J. W., An, S. I., Jun S. Y., Park, H. J., and Yeh, S. W.: ENSO and East Asian winter monsoon relationship modulation associated with the anomalous northwest Pacific anticyclone, Clim. Dynam., 49, 1157-1179, https://doi.org/10.1007/s00382016-3371-5, 2017.

Larkin, N. K. and Harrison, D. E.: On the definition of El Niño and associated seasonal average U.S. weather anomalies, Geophys. Res. Lett., 32, 435-442, https://doi.org/10.1029/2005gl022738, 2005.
Levine, A. F. and Jin, F. F.: Noise-induced instability in the ENSO recharge oscillator, J. Atmos. Sci., 67, 529-542, https://doi.org/10.1175/2009jas3213.1, 2010.

Li, J., Carlson, B. E., and Lacis, A. A.: El Niño-Southern Oscillation correlated aerosol Ångström exponent anomaly over the tropical Pacific discovered in satellite measurements, J. Geophys. Res., 116, D20204, https://doi.org/10.1029/2011jd015733, 2011.

Li, K., Liao, H., Cai, W. J., and Yang, Y.: Attribution of Anthropogenic Influence on Atmospheric Patterns Conducive to Recent Most Severe Haze Over Eastern China, Geophys. Res. Lett., 45, 2072-2081, https://doi.org/10.1002/2017gl076570, 2018.

Li, Q., Zhang, R. H., and Wang, Y.: Interannual variation of the wintertime fog-haze days across central and eastern China and its relation with East Asian winter monsoon, Int. J. Climatol., 36, 346-354, https://doi.org/10.1002/joc.4350, 2016.

Li, S. L., Han, Z., and Chen, H. P.: A comparison of the effects of interannual Arctic sea ice loss and ENSO on winter haze days: observational analyses and AGCM simulations, J. Meteorol. Res.PRC, 31, 820-833, https://doi.org/10.1007/s13351-017-7017-2, 2017.

Li, Z., Smith, K. A., and Cappa, C. D.: Influence of relative humidity on the heterogeneous oxidation of secondary organic aerosol, Atmos. Chem. Phys., 18, 14585-14608, https://doi.org/10.5194/acp-18-14585-2018, 2018.

Liu, P. F., Zhao, C. S., Göbel, T., Hallbauer, E., Nowak, A., Ran, L., Xu, W. Y., Deng, Z. Z., Ma, N., Mildenberger, K., Henning, S., Stratmann, F., and Wiedensohler, A.: Hygroscopic properties of aerosol particles at high relative humidity and their diurnal variations in the North China Plain, Atmos. Chem. Phys., 11, 3479-3494, https://doi.org/10.5194/acp-11-3479-2011, 2011.

Liu, T., Gong, S., He, J., Yu, M., Wang, Q., Li, H., Liu, W., Zhang, J., Li, L., Wang, X., Li, S., Lu, Y., Du, H., Wang, Y., Zhou, C., Liu, H., and Zhao, Q.: Attributions of meteorological and emission factors to the 2015 winter severe haze pollution episodes in China's Jing-Jin-Ji area, Atmos. Chem. Phys., 17, 2971-2980, https://doi.org/10.5194/acp-17-2971-2017, 2017.

Ma, Q. X., Wu, Y. F., Zhang, D. Z., Wang, X. J., Xia, Y. J., Liu, X. Y., Tian, P., Han, Z. W., Xia, X. G., Wang, Y., and Zhang, R. J.: Roles of regional transport and heterogeneous reactions in the $\mathrm{PM}_{2.5}$ increase during winter haze episodes in Beijing, Sci. Total Environ., 599-600, 246-253, https://doi.org/10.1016/j.scitotenv.2017.04.193, 2017.

Miao, Y., Guo, J., Liu, S., Liu, H., Li, Z., Zhang, W., and Zhai, P.: Classification of summertime synoptic patterns in Beijing and their associations with boundary layer structure affecting aerosol pollution, Atmos. Chem. Phys., 17, 3097-3110, https://doi.org/10.5194/acp-17-3097-2017, 2017.

$\mathrm{Mu}, \mathrm{M}$. and Ren, H. L.: Enlightenments from researches and predictions of 2014-2016 super El Niño event, Sci. China Earth Sci., 60, 1569-1571, https://doi.org/10.1007/s11430-017-9094$5,2017$.

Nguyen, T. B., Roach, P. J., Laskin, J., Laskin, A., and Nizkorodov, S. A.: Effect of humidity on the composition of isoprene photooxidation secondary organic aerosol, Atmos. Chem. Phys., 11, 6931-6944, https://doi.org/10.5194/acp-11-6931-2011, 2011.

Rajeev, P., Rajput, P., and Gupta, T.: Chemical characteristics of aerosol and rain water during an El Niño and PDO influenced Indian summer monsoon, Atmos. Environ., 145, 192-200, https://doi.org/10.1016/j.atmosenv.2016.09.026, 2016. 
Ren, H. L., Sun, C. H., Ren, F. M., Yuan, Y., Lu, B., Tian, B., Zuo, J. Q., Liu, Y., Cao, L, Han, R. Q., Jia, X. L., and Liu, C. Z.: Identification method for El Niño/La Niña events, The People's Republic China's National Standard GB/T 33666-2017, May 2017, Standards Press of China, Beijing, 1-6, 2017.

Richman, M. B.: Obliquely rotated principal components: an improved meteorological map typing technique?, J. Appl. Meteorol., 20, 1145-1159, https://doi.org/10.1175/15200450(1981)020<1145:ORPCAI>2.0.CO;2, 1981.

Roberts, A., Guckenheimer, J., Widiasih, E., Timmermann, A., and Joner, C. K. R. T.: Mixed-mode oscillations of El Niño-southern oscillation, J. Atmos. Sci., 73, 1755-1766, https://doi.org/10.1175/JAS-D-15-0191.1, 2016.

Schichtel, B. A., Husar, R. B., Falke, S. R., and Wilson, W. E.: Haze trends over the United States, 1980-1995, Atmos. Environ., 35, 5205-5210, https://doi.org/10.1016/s1352-2310(01)00317$\mathrm{x}, 2001$.

Schneider, U., Becker, A., Finger, P., Christoffer, A. M., Ziese, M., and Rudolf, B.: GPCC's new land surface precipitation climatology based on quality-controlled in situ data and its role in quantifying the global water cycle, Theor. Appl. Climatol., 115, 15-40, https://doi.org/10.1007/s00704-013-0860-x, 2014.

Shaheen, R., Abauanza, M., Jackson, T. L., McCabe, J., Savarino, J., and Thiemens, M. H.: Tales of volcanoes and El- Niño southern oscillations with the oxygen isotope anomaly of sulfate aerosol, P. Natl. Acad. Sci. USA, 110, 17662-17667, https://doi.org/10.1073/pnas.1213149110, 2013.

Sun, J. R., Li, H. Y., Zhang, W. J., Li, T. R., Zhao, W., Zuo, Z. Y., Guo, S., Wu, D., and Fan, S. J.: Modulation of the ENSO on Winter Aerosol Pollution in the Eastern Region of China, J. Geophys. Res.-Atmos., 11, 952-969, https://doi.org/10.1029/2018jd028534, 2018.

Sun, Y. L., Wang, Z. F., Fu, P. Q., Jiang, Q., Yang, T., $\mathrm{Li}$, J., and Ge, X. L.: The impact of relative humidity on aerosol composition and evolution processes during wintertime in Beijing, China, Atmos. Environ., 77, 927-934, https://doi.org/10.1016/j.atmosenv.2013.06.019, 2013.

Timmermann, A., An, S. I., Kug, J. S., Jin, F. F., Cai, W. J., Capotondi, A., Cobb, K., Lengaigne, M., McPhaden, M. J., Stuecker, M. F., Stein, K., Wittenberg, A. T., Yun, K. S., Bayr, T., Chen, H. C., Chikamoto, Y., Dewitte, B., Dommenget, D., Grothe, P., Guilyardi, E., Ham, Y. G., Hayashi, M., Ineson, S., Kang, D., Kim, S., Kim, W. M., Lee, J. L., Li, T., Luo, J. J., McGregor, S., Planton, Y., Power, S., Rashid, H., Ren, H. L., Santoso, A., Takahashi, K., Todd, A., Wang, G. M., Wang, G. J., Xie, R. H., Yang, W. H., Yeh, S. W., Yoon, J., Zeller, E., and Zhang, X. B.: El Niño-Southern Oscillation complexity, Nature, 559, 535-545, https://doi.org/10.1038/s41586-018-0252-6, 2018.

Wang, G. H., Zhang, R. Y., Gomez, M. E., Yang, L. X., Zamora, M. L., Hu, M., Lin, Y., Peng, J. F., Guo, S., Meng, J. J., Li, J. J., Cheng, C. L., Hu, T. F., Ren, Y. Q., Wang, Y. S., Gao, J., Cao, J. J., An, Z. S., Zhou, W. J., Li, G. H., Wang, J. Y., Tian, P. F., Marrero-Ortiz, W., Secrest, J., Du, Z. F., Zheng, J., Shang, D. J., Zeng, L. M., Shao, M., Wang, W. G., Huang, Y., Wang, Y., Zhu, Y. J., Li, Y. X., Hu, J. X., Pan, B. W., Cai, L., Cheng, Y. T., Ji, Y. M., Zhang, F., Rosenfeld, D., Liss, P. S., Duce, R. A., Kolb, C. E., and Molina, M. J.: Persistent sulfate formation from London Fog to Chinese haze, P. Natl. Acad. Sci. USA, 113, 13630-13635, https://doi.org/10.1073/pnas.1616540113, 2016.
Wang, H.-J. and Chen, H.-P.: Understanding the recent trend of haze pollution in eastern China: roles of climate change, Atmos. Chem. Phys., 16, 4205-4211, https://doi.org/10.5194/acp16-4205-2016, 2016.

Wang, R. and Ren, H. L.: The linkage between two ENSO types/modes and the interdecadal changes of ENSO around the year 2000, Atmos. Oceanic Sci. Lett., 10, 168-174, https://doi.org/10.1080/16742834.2016.1258952, 2017.

Warren, B., Austin, R. L., and Cocker, D. R.: Temperature dependence of secondary organic aerosol, Atmos. Environ., 43, 35483555, https://doi.org/10.1016/j.atmosenv.2009.04.011, 2009.

Wu, D., Wu, X. J., Li, F., Tan, H. B., Chen, J., Cao, Z. Q., Sun, X., Chen, H. H., and Li, H. Y.: Temporal and spatial variation of haze during 1951-2005 in Chinese mainland, Act. Meteorol. Sin., 68, 680-688, https://doi.org/10.3788/gzxb20103906.0998, 2010.

Wu, P., Ding, Y. H., Liu, Y. J., and Li, X. C.: Influence of the East Asian winter monsoon and atmospheric humidity on the wintertime haze frequency over central-eastern China, Act. Meteorol. Sin., 74, 352-366, https://doi.org/10.11676/qxxb2016.029, 2016.

Wyrtki, K.: El Niño-the dynamic response of the equatorial Pacific Ocean to atmospheric forcing, J. Phys. Oceanogr., 5, 572-584, 1975.

Xu, X., Zhao, T., Liu, F., Gong, S. L., Kristovich, D., Lu, C., Guo, Y., Cheng, X., Wang, Y., and Ding, G.: Climate modulation of the Tibetan Plateau on haze in China, Atmos. Chem. Phys., 16, 1365-1375, https://doi.org/10.5194/acp-16-1365-2016, 2016.

Yin, Z. and Wang, H.: The strengthening relationship between Eurasian snow cover and December haze days in central North China after the mid-1990s, Atmos. Chem. Phys., 18, 4753-4763, https://doi.org/10.5194/acp-18-4753-2018, 2018.

Yuan, Y. and Song, G.: Impacts of Different Types of El Niño on the East Asian Climate: Focus on ENSO Cycles, J. Climate, 25, 7702-7722, https://doi.org/10.1175/jcli-d-11-00576.1, 2012.

Yu, X. C., Wang, Z. L., Zhang, H., and Zhao, S. Y.: Impacts of different types and intensities of El Niño events on winter aerosols over China, Sci. Total Environ., 655, 766-780, https://doi.org/10.1016/j.scitotenv.2018.11.090, 2019.

Zhang, J. P., Zhu, T., Zhang, Q. H., Li, C. C., Shu, H. L., Ying, Y., Dai, Z. P., Wang, X., Liu, X. Y., Liang, A. M., Shen, H. X., and Yi, B. Q.: The impact of circulation patterns on regional transport pathways and air quality over Beijing and its surroundings, Atmos. Chem. Phys., 12, 5031-5053, https://doi.org/10.5194/acp12-5031-2012, 2012.

Zhang, Q., Zheng, Y. X., Tong, D., Shao, M., Wang, S. X., Zhang, Y. H., Xu, X. D., Wang, J. N., He, H., Liu, W. Q., Ding, Y. H., Lei, Y., Li, J. H., Wang, Z. F., Zhang, X. Y., Wang, Y. S., Cheng, J., Liu, Y., Shi, Q. R., Yan, L., Geng, G. N., Hong, C. P., Li, M., Liu, F., Zheng, B., Cao, J. J., Ding, A. J., Gao, J., Fu, Q. Y., Huo, J. T., Liu, B. X., Liu, Z. R., Yang, F. M., He, K. B., and Hao, J. M.: Drivers of improved $\mathrm{PM}_{2.5}$ air quality in China from 2013 to 2017, P. Natl. Acad. Sci. USA, 116, 24463-2446, https://doi.org/10.1073/pnas.1907956116, 2019.

Zhang, R. H., Li, Q., and Zhang, R. N.: Meteorological conditions for the persistent severe fog and haze event over eastern China in January 2013, Sci. China Earth Sci., 57, 26-35, https://doi.org/10.1007/s11430-013-4774-3, 2014.

Zhang, X., Zhong, J., Wang, J., Wang, Y., and Liu, Y.: The interdecadal worsening of weather conditions affecting aerosol pol- 
lution in the Beijing area in relation to climate warming, Atmos. Chem. Phys., 18, 5991-5999, https://doi.org/10.5194/acp18-5991-2018, 2018.

Zhang, X. Y., Xu, X. D., Ding, Y. H., Liu, Y. J., Zhang, H. D., Wang, Y. Q., and Zhong, J. T.: The impact of meteorological changes from 2013 to 2017 on $\mathrm{PM}_{2.5}$ mass reduction in key regions in China, Sci. China Earth Sci., 49, 1-18, https://doi.org/10.1007/s11430-019-9343-3, 2019.

Zhao, S., Zhang, H., and Xie, B.: The effects of El NiñoSouthern Oscillation on the winter haze pollution of China, Atmos. Chem. Phys., 18, 1863-1877, https://doi.org/10.5194/acp18-1863-2018, 2018.
Zheng, B., Tong, D., Li, M., Liu, F., Hong, C., Geng, G., Li, H., Li, X., Peng, L., Qi, J., Yan, L., Zhang, Y., Zhao, H., Zheng, Y., He, K., and Zhang, Q.: Trends in China's anthropogenic emissions since 2010 as the consequence of clean air actions, Atmos. Chem. Phys., 18, 14095-14111, https://doi.org/10.5194/acp-18-140952018, 2018.

Zhong, J., Zhang, X., Dong, Y., Wang, Y., Liu, C., Wang, J., Zhang, Y., and Che, H.: Feedback effects of boundary-layer meteorological factors on cumulative explosive growth of $\mathrm{PM}_{2.5}$ during winter heavy pollution episodes in Beijing from 2013 to 2016 , Atmos. Chem. Phys., 18, 247-258, https://doi.org/10.5194/acp18-247-2018, 2018. 